\title{
HUBUNGAN ANTARA WAKTU TUNGGU PELAYANAN RESEP RACIKAN TERHADAP KEPUASAN PASIEN DI APOTEK MEDIRA FARMA KOTA BENGKULU BULAN APRIL TAHUN 2021
}

\author{
Nova Yustisia ${ }^{1)}$, Riana Versita ${ }^{* 2)}$, Sefty Yolanda ${ }^{3)}$, Dwi Dominica $^{4)}$ \\ 1,2,3D3 Farmasi, Fakultas Matematika dan Ilmu Pengetahuan Alam, Universitas Bengkulu \\ E-mail: riana.versita@unib.ac.id
}

\begin{abstract}
Pharmaceutical service is a direct and responsible service to patients related to pharmaceutical preparations with the aim of achieving definite results to improve the quality of life of patients. One of the pharmaceutical service standards is the waiting time (response time) for prescription services. The purpose of this study was to determine the relationship between waiting time for concoction prescription services and patient satisfaction at the Medira Farma Pharmacy, Bengkulu City in April 2021. This study used an observational analytic method with a cross sectional study approach and the research instrument was a list of questions (questionnaires) about the relationship between between patient satisfaction and waiting time for the preparation of a prescription at the Medira Farma Pharmacy, Bengkulu City. Questionnaires were obtained from previous research that had previously been tested for validity and reliability. The sample of this study was 30 respondents. determined using purposive sampling technique. Data analysis was carried out by using chi square statistical test. The results of the study showed that the level of patient satisfaction at Medira Farma Pharmacy was $86.67 \%$ satisfied and $13.33 \%$ dissatisfied, while the waiting time for concoction prescription services at Medira Farma Pharmacy was according to the standard of $73.33 \%$ and not according to standard by $26.67 \%$. In the chi square statistical test, the $\mathrm{p}$ value $=0.257$ with the value $=0.05$. The results of the data can be concluded that there is no relationship between waiting time for concoction prescription services and patient satisfaction at the Medira Farma Pharmacy, Bengkulu City with a closeness level of 0.23 which means low. The advice given is that Medira Farma Pharmacy should provide comfortable and adequate waiting room facilities to avoid patients feeling bored.
\end{abstract}

Keywords: Waiting Time, Patient Satisfaction.

\section{ABSTRAK}

Pelayanan kefarmasian adalah suatu pelayanan langsung dan bertanggung jawab kepada pasien yang berkaitan dengan sediaan farmasi dengan maksud mencapai hasil yang pasti untuk meningkatkan mutu kehidupan pasien. Salah satu standar pelayanan farmasi adalah waktu tunggu (respon time) pelayanan resep. Tujuan penelitian ini adalah untuk mengetahui hubungan antara waktu tunggu pelayanan resep racikan terhadap kepuasan pasien di Apotek Medira Farma Kota Bengkulu pada bulan April tahun 2021. Penelitian ini menggunakan metode analitik observasional dengan pendekatan studi cross sectional dan Instrumen penelitian berupa daftar pertanyaan (kuesioner) tentang Hubungan antara kepuasan pasien dengan waktu tunggu pengerjaan resep racikan di Apotek Medira Farma Kota Bengkulu. Kuesioner diperoleh dari penelitian terdahulu yang sebelumnya sudah dilakukan uji validitas dan reliabilitas, .Sampel penelitian ini dengan jumlah 30 responden. yang ditentukan menggunakan teknik purposive sampling. Analisis data dilakukan dengan uji statistik chi square.. Hasil penelitian tingkat kepuasan pasien di Apotek Medira Farma yang menyatakan puas sebesar $86,67 \%$ dan tidak puas sebesar $13,33 \%$, sedangkan waktu tunggu pelayanan resep racikan di Apotek Medira Farma dikatakan sesuai standar sebesar 73,33\% dan tidak sesuai standar sebesar 26,67\%. Pada uji statistik chi square diperoleh nilai $\mathrm{p}=0,257$ dengan nilai $\alpha=0,05$. Hasil data dapat disimpulkan bahwa tidak ada hubungan antara waktu tunggu pelayanan resep racikan terhadap kepuasan pasien di Apotek Medira farma Kota bengkulu dengan tingkat keeratan 0,23 yang berarti rendah. Saran yang diberikan sebaiknya Apotek Medira Farma menyediakan fasilitas ruang tunggu yang nyaman dan memadai untuk menghindari pasien merasa jenuh.

Kata kunci : Waktu Tunggu, Kepuasan Pasien. 


\section{PENDAHULUAN}

Pelayanan kefarmasian adalah suatu pelayanan langsung dan bertanggung jawab kepada pasien yang berhubungan dengan sediaan farmasi untuk meningkatkan kualitas hidup pasien. Fasilitas pelayanan kesehatan adalah suatu tempat yang digunakan untuk menyelenggarakan upaya pelayanan kesehatan (Herlambang dkk, 2016; Kristiany dkk, 2018). Fasilitas dalam pelayanan kesehatan salah satunya adalah Apotek. Apotek adalah sarana pelayanan kefarmasian tempat dilakukan praktek kefarmasian bagi apoteker (Permenkes, 2016; Permenkes, 2008). Standar pelayanan kefarmasian di apotek adalah tolak ukur yang dilaksanakan sebagai pedoman bagi tenaga kefarmasian dalam mewujudkan pelayanan kefarmasian yang prima (Permenkes 73, 2016). Salah satu standar minimal pelayanan kefarmasian adalah waktu tunggu. Lama waktu tunggu pelayanan resep dapat mempengaruhi kepuasan pasien. Standar waktu pelayanan resep menurut Kementrian Kesehatan Republik Indonesia yang tertuang dalam Permenkes Nomor 73 tahun 2016 untuk resep non racikan 30 menit dan resep racikan 60 menit (Permenkes, 2016).

Berdasarkan hasil survei di Apotek Medira Farma pada awal penelitian di dapatkan bahwa 2 orang dari 5 orang pasien mengatakan puas terhadap waktu tunggu pelayanan resep racikan dan 3 orang pasien mengatakan tidak puas dengan alasan tempat tunggu yang terbatas akibat pandemi Covid-19, dan tempat tunggu yang berada diluar ruangan yang menyebabkan tidak nyaman. Tujuan dari penelitian ini adalah untuk mengetahui hubungan antara waktu tunggu pelayanan resep racikan terhadap kepuasan pasien di Apotek Medira Farma Kota Bengkulu pada bulan April tahun 2021.

\section{METODE PENELITIAN}

Penelitian ini merupakan jenis penelitian analitik observasional menggunakan skema Cross Sectional (Notoatmodjo, Soekidjo, 2010; Noor J, 2012). Lokasi penelitian adalah di Apotek Medira Farma yang beralamat di jalan Jl. MT. Haryono No.09 RT. 12 RW. 04 Kota Bengkulu. Penelitian ini dilakukan selama kurang lebih 1 bulan pada bulan April. Subyek penelitian adalah pasien yang menunggu pelayan resep di Apotek Medira Farma sebagai 
responden. Penelitian ini dilakukan dengan cara membagikan kuesioner kepada responden dan menghitung waktu tunggu sejak resep diserahkan sampai responden mendapatkan obat disertai informasi obat dengan menggunakan stopwatch (Arikunto S, 2013). Penentuan jumlah sampel atau responden pada penelitian ini memakai rumus Slovin, yaitu jumlah pasien yang menebus resep racikan di Apotek Medira Farma dalam waktu 1 bulan adalah sejumlah 42 resep, sehingga diperoleh besar sampel 30 responden sesuai dengan kriteria inklusi, menggunakan teknik purposive sampling (Arikunto S, 2013; Dahlan M, 2013; Wibowo A, 2012; Wijayanti T, 2012).

\section{Metode Pengukuran Kepuasan Pasien}

Menurut Muninjaya (2013) dalam mengukur kepuasan pasien ada beberapa meteode yang digunakan seperti: Sistem keluhan dan saran, Ghost shopping (Pembelanjaan misterius), Lost Costumer Analysis dan Survei kepuasan pelanggan. Pada Metode survei kepuasan pelanggan dapat dilakukan dengan cara sebagai berikut: Pengukuran dapat dilakukan langsung melalui pertanyaan kepada pelanggan dengan ungkapan sangat puas, puas, cukup puas, tidak puas atau sangat tidak puas, yang kedua responden diberi pertanyaan mengenai seberapa besar mereka mengharapkan suatu atribut tertentu dan seberapa besar yang mereka rasakan, ketiga yaitu responden diminta untuk menuliskan perbaikan-perbaikan yang mereka sarankan dan terakhir responden diminta meranking elemen atau atribut penawaran berdasarkan derajat kepentingan setiap elemen seberapa baik kinerja perusahaan pada masing-masing elemen.

\section{Faktor-faktor yang mempengaruhi Kepuasan Pasien}

Berdasarkan Kotler dan Keller (2016) ada empat faktor yang dapat menilai kepuasan pasien yaitu : Kualitas produk atau jasa, penderita akan merasa puas bila hasil penilaian mereka menunjukan bahwa produk atau jasa yang digunakan berkualitas yang dipengaruhi oleh dua hal yaitu kenyataan kualitas produk atau jasa dan komunikasi yang kedua yaitu kualitas pelayanaan dimana penderita tentu merasa puas apabila mendapatkan pelayanan yang baik atau sesuai yang diharapakan dan Faktor emosional dan terakhir yaitu penderita merasa bangga, puas dan kagum terhadap pelayanan yang diberikan. 


\section{Aspek ketika mengukur kualitas pelayanan}

Menurut Algifari (2016) dan Nursalam (2011) ketika mengukur kualitas pelayanan ada lima aspek dikenal dengan 'servaqual' atau service quality, yaitu: Tangible (bukti fisik), yaitu performa fasilitas fisik, peralatan, personel dan sarana komunikasi, Reliability (kehandalan) yaitu kemampuan untuk melaksanakan jasa yang disajikan dengan tepat dan terpercaya dan Responsiveness (ketanggapan) yaitu kecakapan membantu pelanggan dan melayani dengan cepat atau tanggap. Sedangkan Assurance (jaminan), yaitu pemahaman dan kesopanan karyawan cara mereka memberikan kepercayaan atau keyakinan pelanggan, memiliki empat subdimensi, diantaranya: Competence, Credibility, Courtessy, Security

\section{Sampel Penelitian}

Teknik pengumpulan sampel pada riset ini menggunakan teknik purposive sampling yaitu teknik menggunakan kriteria yang sudah dipilih peneliti. Penentuan jumlah sampel menggunakan rumus Slovin:

$$
\begin{array}{rlrl}
n=\frac{\mathrm{N}}{1+N(e)^{2}} & \\
n=\frac{42}{1+420(0,1)^{2}} & \text { Keterangan : } \\
n=\frac{42}{1,42} & \mathrm{~N}=\text { Jumlah sampel } \\
n=29,57 & \mathrm{e}=\text { Tingkat Kesalahan Sampel (10\%) } \\
n=30 \text { Responden } & \text { Jumlah populasi 42 pasien dengan margin error } \\
& \text { (tingkat kesalahan 10\%) }
\end{array}
$$

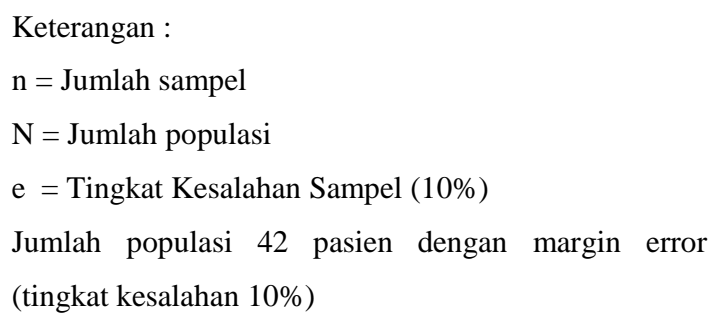

Sampel pada penelitian ini berjumlah 30 responden, ciri-ciri khusus yang akan diambil sesuai dengan kriteria inklusi dan eksklusi. Menurut sani (2017), penentuan kriteria sampel sangat membantu peneliti untuk mengurangi terjadinya bias hasil penelitian. Adapun jenis-jenis kriteria pada penelitian ini yaitu kriteria inklusi dimana semua atau keluarga yang datang dengan resep racikan, bias menulis, mendengar dan membaca, Pasien telah berobat minimal dua kali ke apotek Medira Farma dan bersedia menjadi responden, sedangkan kriteria Eksklusi yaitu semua pasien yang dating tanpa resep, dan tida bersedia menjadi responden. 


\section{HASIL DAN PEMBAHASAN}

\section{Karakteristik Responden}

Karakteristik responden adalah ciri atau identitas secara universal yang dimiliki responden. Karakteristik pada riset ini mencakup jenis kelamin, usia, pendidikan dan pekerjaan. Berdasarkan karakteristik penderita berdasarkan jenis kelamin, perempuan memiliki persentase tertinggi, yaitu sebanyak 20 responden $(66,67 \%)$. Situasi ini terjadi disebabkan peneliti mengambil sampel secara acak sesuai jumlah kuota tanpa menilai penelusuran sampel bersumber pada jenis kelamin. Menurut Gunarsa (2008), jenis kelamin mempunyai pengaruh pandangan atau kepuasan terhadap pelayanan yang diberikan. Perempuan cenderung melihat penampilan secara terperinci, sementara laki-laki tidak mengindahkan hal tersebut. Cara mengelola hubungan bagi kaum laki-laki, cenderung lebih acuh tak acuh dibandingkan hal yang dikemukakan perempuan. Sebab itu laki-laki dianggap lebih fleksibel dibandingkan perempuan terkait dengan kepuasan pelayanan (Gunarsa, 2008).

Pada kelompok usia dapat dilihat rentang usia 31 - 40 tahun mempunyai persentase tertinggi, yaitu sebanyak 21 responden $(26,67 \%)$. Usia responden hamper semuanya ada pada usia produktif yaitu 31-40 tahun (Depkes RI, 2007). Usia produktif merupakan usia yang rawan terserang penyakit karena pada usia produktif seseorang jarang memperhatikan kesehatan, seperti makan sembarangan dan pola hidup yang tidak sehat dan merokok (Dhianingtyas, 2006). Gunarsa (2008) mengatakan bahwa bertambahnya usia seseorang dapat berdampak pada emosional atau kepuasan seseorang terhadap jasa pelayanan, seseorang berusia tua cenderung lebih bersifat terbuka, sehingga pasien berusia tua harapannya lebih rendah dari pasien berusia muda. Situasi ini menyebabkan pasien tua lebih merasa cepat puas terhadap jasa pelayanan kesehatan.

Distribusi frekuensi karakteristik responden berdasarkan pendidikan menunjukkan bahwa yang Sekolah Menengah Atas (SMA) lebih dominan dibandingkan dengan tingkat pendidikan lainnya, yaitu sebanyak 19 responden $(63,33 \%)$. Hal ini disebabkan berdasarkan data kependudukan Bengkulu bahwa mayoritas penduduknya memiliki latar belakang pendidikan terakhir SMA. 
Berdasarkan pekerjaan responden, dari hasil penelitian dapat diketahui bahwa pekerjaan lain-lain memiliki persentase paling tinggi, yaitu sebanyak 11 responden $(36,67 \%)$. Pekerjaan lain-lain yang dimaksud adalah ibu rumah tangga dan buruhsehingga dapat disimpulkan bahwa sebagian besar pasien yang menebus resep obat racikan di Apotek Medira Farma Kota Bengkulu, yaitu ibu rumah tangga.

Tabel 1 Karakteristik responden

\begin{tabular}{|c|c|c|c|}
\hline No & Variabel & Jumlah & Persentase \% \\
\hline 1 & $\begin{array}{l}\text { Jenis kelamin } \\
\text { 1. Perempuan } \\
\text { 2. Laki-Laki }\end{array}$ & $\begin{array}{l}20 \text { responden } \\
10 \text { responden }\end{array}$ & $\begin{array}{l}66,67 \% \\
33,33 \%\end{array}$ \\
\hline & Total & 30 responden & $100 \%$ \\
\hline 2 & $\begin{array}{l}\text { Usia }^{\delta} \\
\text { 1. } 20-30 \text { Tahun } \\
\text { 2. } 31-40 \text { Tahun } \\
\text { 3. } 41-50 \text { Tahun } \\
\text { 4. }>50 \text { Tahun }\end{array}$ & $\begin{array}{l}7 \text { responden } \\
15 \text { responden } \\
4 \text { responden } \\
4 \text { responden }\end{array}$ & $\begin{array}{l}23,33 \% \\
50 \% \\
13,33 \% \\
13,33 \% \\
\end{array}$ \\
\hline & Total & 30 responden & $100 \%$ \\
\hline 3 & $\begin{array}{l}\text { Pendidikan terakhir } \\
\text { 1. SD } \\
\text { 2. SMP } \\
\text { 3. SMA } \\
\text { 4. SARJANA }\end{array}$ & $\begin{array}{l}2 \text { responden } \\
2 \text { responden } \\
19 \text { responden } \\
7 \text { responden }\end{array}$ & $\begin{array}{l}6.67 \% \\
6,67 \% \\
63,33 \% \\
23,33 \%\end{array}$ \\
\hline & Total & 30 responden & $100 \%$ \\
\hline 4 & $\begin{array}{l}\text { Pekerjaan } \\
\text { 1. PNS } \\
\text { 2. Swasta } \\
\text { 3. Petani } \\
\text { 4. Mahasiswa } \\
\text { 5. Pedagang } \\
\text { 6. Lain-Lain } \\
\end{array}$ & $\begin{array}{ll}4 & \text { responden } \\
3 & \text { responden } \\
1 & \text { responden } \\
3 & \text { responden } \\
8 & \text { responden } \\
11 & \text { responden }\end{array}$ & $\begin{array}{l}13,33 \% \\
10 \% \\
3,33 \% \\
10 \% \\
26,67 \% \\
36,67 \%\end{array}$ \\
\hline & Total & 30 responden & $100 \%$ \\
\hline
\end{tabular}

${ }^{\delta}$ Sumber : Data Primer, Klasifikasi berdasarkan Depkes 2009

\section{Distribusi frekuensi waktu tunggu pelayanan obat racikan di Apotek Medira Farma Kota Bengkulu"}

Pada tabel 2 diperoleh bahwa dari 30 responden di Apotek Medira Farma Kota Bengkulu, sebanyak 22 pasien $(73,33 \%)$ responden mengatakan waktu tunggu pelayanan resep obat racikan sesuai standar, sedangkan 8 pasien $(26,67 \%)$ mengatakan waktu tunggu pelayanan resep obat racikan tidak sesuai standar. Berdasarkan Peraturan Menteri Kesehatan Republik Indonesia Nomor 73 Tahun 2016 tentang standar Pelayanan Kefarmasian di Apotek, lama waktu pelayanan resep obat racikan adalah 60 menit. 
Jumlah item obat racikan yang terdapat dalam lembar resep mempengaruhi lama waktu yang diperlukan oleh petugas apotek untuk mempersiapkan obat sehingga akan berpengaruh terhadap waktu tunggu dan kepuasan pasien terhadap pelayanan Hal ini sebaiknya dijadikan tantangan bagi petugas Apotek untuk terus meningkatkan kecepatan dan ketelitian dalam membaca resep dan menyiapkan obat yang pada akhirnya dapat mempersingkat waktu tunggu dan meningkatkan kepuasan pasien terhadap pelayanan Apotek. Akumulasi resep pada jam kunjungan pasien yang bersamaan juga berdampak terhadap waktu tunggu pelayanan. Untuk itu perlu ada metode pengelolaan sumber daya manusia (SDM) yang baik seperti menempatkan tenaga teknis kefarmasian dan apoteker lebih banyak pada jam sibuk apotek. Jumlah SDM memadaiakan sangat berpengaruh pada kecepatan pelayanan obat di Apotek Medira Farma Kota Bengkulu.

Tabel 2 Distribusi frekuensi waktu tunggu pelayanan resep racikan di Apotek Medira Farma

\begin{tabular}{lcc}
\multicolumn{1}{c}{ Variabel Waktu Tunggu $^{\delta}$} & Frekuensi (n) & Persentase \% \\
\hline Sesuai Standar & 22 & $73,33 \%$ \\
Tidak Sesuai Standar & 8 & $26,67 \%$ \\
\hline Total" & 30 & 100
\end{tabular}

${ }^{\delta}$ Sumber: Data Primer (Permenkes No 73, 2016)

Tabel 3 Waktu Tunggu Pelayanan Resep Berdasarkan Nomor Resep dan Jam Pelayanan di Apotek Medira Farma

\begin{tabular}{rlcc}
\hline No & Jenis Resep & \multicolumn{2}{c}{ Resep diterima pada pukul } \\
\hline & & $\mathbf{1 0 . 0 0 - 1 6 . 0 0}$ (Shif Pagi) & $\mathbf{1 6 . 0 0 - 2 2 . 0 0}$ (Shif Sore) \\
\hline 1 & Racikan & Waktu Tunggu(menit) & Waktu Tunggu (menit) \\
\hline 2 & Racikan & 64,4 & - \\
\hline 3 & Racikan & 35,2 & - \\
\hline 4 & Racikan & - & 29,50 \\
\hline 5 & Racikan & - & - \\
\hline 6 & Racikan & - & 37,80 \\
\hline 7 & Racikan & - & 27,80 \\
\hline 8 & Racikan & - & 24,40 \\
\hline 9 & Racikan & - & 64,40 \\
\hline 10 & Racikan & 32,20 & 30,10 \\
\hline 11 & Racikan & - & - \\
\hline 12 & Racikan & - & 61,80 \\
\hline 13 & Racikan & - & 22,30 \\
\hline 14 & Racikan & 60,20 & 61,10 \\
\hline 15 & Racikan & - & - \\
\hline 16 & Racikan & - & 25,40 \\
\hline 17 & Racikan & - & 25,40 \\
\hline 18 & Racikan & - & 62,30 \\
\hline 19 & Racikan & - & 13,80 \\
\hline & & & 37,80 \\
\hline
\end{tabular}




\begin{tabular}{rlcc}
20 & Racikan & 27,50 & - \\
\hline 21 & Racikan & - & 61,50 \\
\hline 22 & Racikan & - & 42,30 \\
\hline 23 & Racikan & - & 22,30 \\
\hline 24 & Racikan & - & 22,30 \\
\hline 25 & Racikan & - & 60,80 \\
\hline 26 & Racikan & - & 32,00 \\
\hline 27 & Racikan & - & 31,00 \\
\hline 28 & Racikan & - & 33,10 \\
\hline 29 & Racikan & - & 35,20 \\
\hline 30 & Racikan & - & 21,20 \\
\hline \multicolumn{2}{c}{ Jumlah Total (menit) } & $\mathbf{2 3 7 , 3 0}$ & $\mathbf{8 8 5 , 6 0}$ \\
\hline \multicolumn{2}{c}{ Rata-rata (menit) } & $\mathbf{3 9 , 5 5 0}$ & $\mathbf{3 6 , 9 0 0}$ \\
\hline
\end{tabular}

${ }^{\delta}$ Sumber: Data Primer (Permenkes No 73, 2016)

\section{Keterangan}

Shif pagi (10.00-16.00) :Jumlah petugas apotek 1 orang TTK

Shif sore (16.00-22.00) : Jumlah petugas Apotek 1 orang Apoteker dan 2 Orang TTK karena pada shif sore buka praktek dokter

Hasil riset, rata-rata waktu tunggu pelayanan resep racikan adalah 39,55 menit pada shif pagi (10.00-16.00) lebih lama sedikit dibandingkan shif sore (16.00-22.00) yaitu 36,9 menit, rata-rata waktu tunggu pelayanan resep racikan sudah sesuai dengan Permenkes 73 tahun 2016 yaitu tidak lebih dari 60 menit, walaupun ada 8 resep yang lebih dari 60 menit

\section{Distribusi frekuensi kepuasan pasien di Apotek Medira Farma Kota Bengkulu}

Kepuasan responden ditentukan oleh berbagai bentuk pelayanan yang didapatkan sewaktu menggunakan sejumlah tahapan pelayanan kesehatan. Ketidakpuasan yang ditemukan pada tahap awal pelayanan memicu persepsi berupa kualitas pelayanan yang buruk untuk tahap berikutnya, sehingga responden merasa tidak puas dengan pelayanan secara keseluruhan. Kepuasan pelanggan merupakan ujung tombak dalam era persaingan saat ini. Pelayanan yang memuaskan akan membuat pasien setia untuk tetap menggunakan jasa yang diberikan. Pelanggan yang loyal akan membuat institusi pemberi pelayanan kesehatan mampu bertahan (Prastiwi, 2007). Pada tabel 4. dapat diketahui bahwa dari 30 responden di Apotek Medira Farma, 26 responden (86,67\%) menyatakan puas sedangkan 4 responden $(13,33 \%)$ yang menyatakan tidak puas.

Tabel 4 Distribusi frekuensi kepuasan pasien di Apotek Medira Farma Kota Bengkulu

\begin{tabular}{lcc}
\hline \multicolumn{1}{c}{ Variabel Kepuasan Pasien } & Frekuensi (n) & Persentase $\%$ \\
\hline Puas & 26 & $86,67 \%$ \\
Tidak Puas & 4 & $13,33 \%$ \\
\hline
\end{tabular}




\begin{tabular}{lcc}
\hline Tota”l & 30 & 100
\end{tabular}

${ }^{\delta}$ Sumber : Data Primer, Klasifikasi Menurut (Kotler, 2016; Prastiwi EN, 2008; Kristiany dkk, 2018; Gunarsa S, 2008; Dewi dkk, 2014)

Tabel 5 Tingkat Kepuasan Pasien

\begin{tabular}{lccc}
\hline Dimensi $^{\circ}$ & Jumlah Skor & Persentase (\%) & Kriteria \\
\hline Kehandalan (reliability) & 338 & 87,27 & Puas \\
\hline Ketanggapan (responsiveness) & 328 & 87,30 & Puas \\
\hline Keyakinan (konfidence) & 333 & 88,20 & Puas \\
\hline Empati (emphaty) & 361 & 83,76 & Puas \\
\hline Bukti Langsung (tangible) & 343 & 86,80 & Puas \\
\hline Rata-rata" & 340 & 86,67 & Puas \\
\hline S Sumber : Klasifikasi menurut Algifari (2016) dan Nursalam (2011)
\end{tabular}

${ }^{\delta}$ Sumber : Klasifikasi menurut Algifari (2016) dan Nursalam (2011)

Hubungan Antara Tingkat Kepuasan Pasien Dengan Waktu Tunggu Pelayanan Resep Racikan di Apotek Medira Farma Kota Bengkulu Bulan April Tahun 2021

Pada Tabel 4 dan 5. dapat diperoleh bahwa dari 30 yang dilayani sesuai standar waktu (60 menit) menyatakan puas dan 4 orang menyatakan tidak puas. Sedangkan dari 8 responden yang mendapatkan pelayanan tidak sesuai standar waktu, 6 responden mengutarakan puas dan 2 responden mengutarakan tidak puas. Sesudah dilakukan analisis bivariat menggunakan uji chi-square diperoleh $\mathrm{p}=0,257>\alpha=0,05$ bahwa (Ho) diterima yang bermakna tidak ada hubungan yang signifikan antara waktu tunggu pelayanan resep obat racikan terhadap kepuasan pasien di Apotek Medira Farma Kota Bengkulu. Sementara untuk keeratan hubungan (pada lampiran) diperoleh Koefisien Kontingensi = 0,23 yang berarti tingkat keeratannya rendah. Tingkat kepuasan pasien yang tinggi probabilitasnya disebabkan responden yang sudah fanatik atau terbiasa menebus resep di Apotek Medira Farma, responden merasa petugas cukup ramah (Utami YT, 2015; Prastiwi EN, 2008 Kristiany F, 2018).

Fasilitas (sarana dan prasarana) yang menunjang seperti adanya media elektronik (televisi), ruang tunggu yang sejuk ber $\mathrm{AC}$ dan bersih, tempat duduk pengunjung yang cukup nyaman, tersajinya media massa (majalah atau koran) untuk dibaca pengunjung saat menunggu akhirnya waktu tunggu yang lebih lama tidak terlalu mengubah tingkat kepuasan pengunjung (Utami YT, 2015; Prastiwi EN, 2008; Kristiany F, 2018). 
Tabel 6. Hubungan antara tingkat kepuasan pasien dengan waktu tunggu pelayanan resep racikan di Apotek Medira Farma Kota Bengkulu Bulan April Tahun 2021

\begin{tabular}{|c|c|c|c|c|c|c|c|}
\hline \multirow{3}{*}{$\begin{array}{l}\text { Variabel Waktu } \\
\text { Tunggu }\end{array}$} & \multicolumn{4}{|c|}{ Variabel Kepuasan } & \multirow{2}{*}{\multicolumn{2}{|c|}{ Total }} & \multirow{2}{*}{ P Value } \\
\hline & \multicolumn{2}{|c|}{ Puas } & \multicolumn{2}{|c|}{ Tidak Puas } & & & \\
\hline & $F$ & $\%$ & $\mathrm{~F}$ & $\%$ & $F$ & $\%$ & 0.257 \\
\hline Sesuai Standar & 20 & $66,67 \%$ & 2 & $6,67 \%$ & 22 & $73,33 \%$ & \\
\hline Tidak Sesuai Standar & 6 & $20 \%$ & 2 & $6,67 \%$ & 8 & $26,67 \%$ & \\
\hline Total & 26 & $86,67 \%$ & 4 & $13,33 \%$ & 30 & $100 \%$ & \\
\hline
\end{tabular}

\section{KESIMPULAN}

Tidak ada hubungan yang signifikan $(\mathrm{p}=0,257)$ antara waktu tunggu pelayanan resep obat racikan dan tingkat kepuasan pasien di Apotek Medira Farma. Sebanyak 86,67\% pasien menyatakan puas terhadap pelayanan meskipun jumlah pasien yang mendapatkan pelayanan sesuai standar waktu tunggu adalah sebesar 73,33 \% dan 26,67 mendapatkan pelayanan tidak sesuai standar waktu tunggu.

\section{DAFTAR PUSTAKA}

Arikunto., Suharsimi. 2013. Prosedur Penelitian Suatu Pendekatan Praktik. Jakarta: Rhineka Cipta

Dahlan, M., Sopiyudin. 2013. Besar Sampel dan Cara Pengambilan Sampel dalam Penelitian Kedokteran dan Kesehatan. Jakarta: Salemba Medika.

Departemen Kesehatan Republik Indonesia. 2007. Standart Pelayanan Minimal Rumah Sakit. Jakarta: Author.

Dewi., Sukma, M. 2014. Hubungan kualitas pelayanan rekam medis dengan tingkat kepuasan pasien pada tempat penerimaan pasien rawat jalan di rumah sakit stroke nasional bukittinggi. KTI. STIKes Dharma Landbouw Padang.

Dhianingtyas., Yunita. 2006. Resiko Obesitas, Kebiasaan Merokok, dan Konsumsi Garam Terhadap Kejadian Hipertensi Pada Usia Produktif. The Indonesian Journal of Public Health. Vol 2 . No 3. 12-29.

Gunarsa, S. 2008. Psikologi Perawatan. Jakarta: Gunung Mulia.

Herlambang., Susatyo. 2016. Manajemen Pelayanan Kesehatan Rumah Sakit Yogyakarta: Gosyen Publishing.

Kemenkes RI Nomor 129/Menkes/SK/II/2008 tentang Standar Pelayanan Rumah Sakit. 
Kementerian Kesehatan Republik Indonesia. 2016. Peraturan Menteri Kesehatan Republik Indonesia Nomor 73 Tahun 2016. Standar Pelayanan Kefarmasian di Apotek, Jakarta: Kementerian Kesehatan Republik Indonesia.

Kotler, P. dan Keller, K.L., 2016. Manajemen Pemasaran, Edisi 13 Jilid 1. Jakarta: Erlangga.

Kristiany, Fanny. 2018. Kualitas Pelayanan Resep Obat Pasien Umum Rawat Jalan Berdasarkan Waktu Tunggu di Instalasi Farmasi Rumah Sakit Umum Daerah Ende Bulann Juni Tahun 2018. [Karya Tulis Ilmiah]. Kupang: Poltekes Kemenkes Kupang.

Noor, Juliansyah. 2012. Metodologi Penelitian. Jakarta: Kencana Prenada Media Group.

Notoatmodjo, Soekidjo. 2010. Metodologi penelitian kesehatan, Jakarta: Rhineka Cipta.

Notoatmodjo, Soekidjo. 2012. Metodologi Penelitian Kesehatan, Jakarta: Rhineka Cipta.

Muninjaya, Gde. A A., (2013). Manajemen Mutu Pelayanan Kesehatan. Jakarta : EGC.

Prastiwi, EN. 2008. Hubungan Kepuasan Pasien Bayar dengan Minat Kunjungan Ulang Di Puskesmas Wisma Jaya Kota Bekasi tahun 2007. Makara Kesehatan. Vol :12. No.1. 42-46.

Umar, Husein. 2013. Metode Penelitian Untuk Skripsi dan Tesis Bisnis Edisi Kedua. Jakarta: PT Rajagrafindo Persada.

Undang Undang RI Nomor. 36 Tahun 2009. Tentang Kesehatan.

Utami, Yeni Tri. 2015. Hubungan Waktu Tunggu Pelayanan Rawat Jalan Dengan Kepuasan Pasien di RSU Assalam Gemolong. Apikes Citra Medika Surakarta.

Wibowo, Adik. 2014. Metodologi Penelitian Praktis Bidang Kesehatan. Jakarta: PT Rajagrafindo Persada.

Wijayanti, Titik. 2012. Managing Marketing Plan Teori dan Aplikasi. Jakarta: PT Elex Media Komputindo. 